\title{
BMJ Open Admissions for orthostatic hypotension: an analysis of NHS England Hospital Episode Statistics data
}

\author{
Eoin Duggan (D) , Roman Romero-Ortuno (D) , Rose Anne Kenny
}

To cite: Duggan E, RomeroOrtuno R, Kenny RA. Admissions for orthostatic hypotension: an analysis of NHS England Hospital Episode Statistics data. BMJ Open 2019;9:e034087. doi:10.1136/ bmjopen-2019-034087

- Prepublication history for this paper is available online. To view these files, please visit the journal online (http://dx.doi org/10.1136/bmjopen-2019034087).

Received 05 September 2019 Revised 30 0ctober 2019 Accepted 04 November 2019

D Check for updates

(c) Author(s) (or their employer(s)) 2019. Re-use permitted under CC BY-NC. No commercial re-use. See rights and permissions. Published by BMJ.

Mercer's Institute for Successful Ageing, St. James's Hospital, Dublin, Ireland

Correspondence to

Dr Eoin Duggan;

eoin.duggan@ucdconnect.ie

\section{ABSTRACT}

Objectives To determine whether admissions for orthostatic hypotension $(\mathrm{OH})$ and its consequences, such as falls, have changed over the past 10 years in the National Health Service (NHS) England.

Setting Data from NHS England Hospital Episode Statistics, a database containing details of all admissions, accident and emergency attendances and outpatient appointments at NHS hospitals in England, were obtained and analysed.

Participants Data on hospital admissions in NHS England, as defined by finished consultant episodes (FCEs), were examined between 2008 and 2017.

Main outcome measures FCEs for the following International Classification of Disease codes were examined: $\mathrm{OH}$ (195.1), tendency to fall (R29.6), epilepsy (G40) and chronic obstructive pulmonary disease (COPD) (J44). The total number of FCEs was also examined.

Results Between 2008 and 2017, FCEs for $\mathrm{OH}$ rose from 14658 to 30759 , a 110\% increase. The greatest increase was in the over 75 years age group where FCEs went from 10639 to 22756 , a $114 \%$ rise. The number of falls related FCEs in this age group rose from 61841 to 89622 (45\%). Admissions for epilepsy and COPD rose by $7 \%$ and $35 \%$, respectively.

Conclusions The number of admissions for $\mathrm{OH}$ has risen dramatically over the past 10 years, as have admissions for falls and related disorders. This rise is out of proportion with admissions for other conditions such as epilepsy and COPD. We postulate that this relates to tighter blood pressure (BP) targets. This suggests caution in the application of recent BP targets to older, frailer adults.

\section{INTRODUCTION}

Our population is ageing and by 2040 nearly one in four people in the UK will be aged 65 years or over. ${ }^{1}$ Orthostatic hypotension $(\mathrm{OH})$, defined as a sustained drop in systolic blood pressure (SBP) by at least $20 \mathrm{~mm} \mathrm{Hg}$ or diastolic blood pressure (DBP) by at least $10 \mathrm{~mm} \mathrm{Hg}$ within $3 \mathrm{~min}$ of standing, ${ }^{2}$ is common affecting 1 in 10 people aged 50 years or over. ${ }^{3} \mathrm{OH}$ is most prevalent in older persons with multimorbidity and frailty. ${ }^{4}$ Agerelated structural and physiological changes such as: increased vascular stiffness, impaired baroreflex sensitivity, impaired autonomic

\section{Strengths and limitations of this study}

- We used a large comprehensive data set, Hospital Episode Statistics, which includes details of all admissions to NHS hospitals in England.

- We examined 10 years of data to establish trends in admissions over a prolonged period.

- We examined control variables chronic obstructive pulmonary disease and epilepsy to try ensure that results were not confounded by overall rises in admissions due to population ageing.

- Limitations include the fact that it is observational data, therefore we cannot infer causation and the possibility of misclassification bias and coding errors.

reflexes, sarcopenia, attenuated reninangiotensin activity, elevated norepinephrine levels, reduced thirst sensation and hypovolaemia contribute to the higher prevalence of $\mathrm{OH}$ and susceptibility to $\mathrm{OH}$ in persons over 75 years. Age-related $\mathrm{OH}$ is a risk factor for injurious and all-cause falls, ${ }^{5}{ }^{6}$ depression, ${ }^{7}$ cognitive decline ${ }^{8}$ and possibly dementia. ${ }^{9}$

Over the past number of years the target for SBP and DBP control in hypertension has progressively declined from $160 \mathrm{~mm} \mathrm{Hg}$ to more recent Systolic Blood Pressure Intervention Trial (SPRINT) targets of $120 \mathrm{~mm}$ Hg. ${ }^{10}$ In 2017 a Cochrane review concluded that 'there is insufficient evidence to know whether a higher BP target (less than 150-160/95-105 mm Hg) or a lower BP target (less than $140 / 90 \mathrm{~mm} \mathrm{Hg}$ ) is better for older adults with high BP'. The review acknowledged however that an 'even lower BP target of less than $140 \mathrm{~mm} \mathrm{Hg}$ is commonly applied to all age groups'.11

Such lower BP targets in the very old are controversial in context of concerns for $\mathrm{OH}$ and subsequent adverse events-in particular falls. ${ }^{12}$

Given the progressive lowering of targets for SBP in hypertension, and the known association between $\mathrm{OH}$ with $\mathrm{CV}$ medications ${ }^{13}$ we 
hypothesise that admissions for $\mathrm{OH}$ have increased over the past 10 years in the National Health Service (NHS) England. Given that falls are commonly associated with $\mathrm{OH}$, we also examined whether hospital admission for falls have risen. These were compared with overall rates of admissions for two other age-related disorders unconnected to hypertension treatment-epilepsy and chronic obstructive pulmonary disease (COPD).

\section{METHODS}

We obtained data from the NHS England Hospital Episode Statistics (HES) database for years 2008 to 2017. HES is a database containing details of all admissions, accident and emergency attendances and outpatient appointments at NHS hospitals in England. Clinical coders based on hospital trusts record diagnosis information using the International Classification of Disease 10th Revision (ICD-10) classification system. Each HES record captures up to 20 diagnosis values, recording the primary reason the patient is being treated and any relevant secondary diagnoses.

We examined admissions as defined by a finished consultant episode (FCE) for a primary diagnosis coded with a selection of ICD-10 codes. An FCE is a continuous period of admitted patient care under one consultant within one healthcare provider.

The ICD-10 codes examined were: $\mathrm{OH}$ (I95.1), tendency to fall (R29.6), epilepsy (G40) and COPD (J44). Admissions for epilepsy and COPD were examined as control variables. Epilepsy was chosen as it is a cause of transient loss of consciousness and falls but is not associated with cardiovascular disease. COPD was chosen as a common disorder whose prevalence increases with age but is not related to cardiovascular disease. The total number of admissions across all diagnoses were also examined. Data for 'Tendency to fall' were available only between 2013 and 2017.

The number of FCEs were split into age groups: under 60 years, 60 to 74 years and 75 years and older. Descriptive statistics were examined in Microsoft Excel.

There was no direct patient or public involvement in this study.

\section{RESULTS}

Over the 10 years from 2008 to 2017, FCEs for $\mathrm{OH}$ rose from 14658 to 30759 , a $110 \%$ increase. The greatest increase was in the over 75 years age group where FCEs increased from 10639 to 22756 , a 114\% rise (figure 1A).

There was a $45 \%$ increase in the number of falls-related FCEs in the over 75 years age group between 2013 and 2017, rising from 61841 to 89622 (figure 1B). Admissions for epilepsy in the over 75 years remained relatively stable in the period 2008-2017 rising from 6820 to $7310(7 \%)$ (figure 1C), while admissions for COPD rose 35\% (77 967 to 104942 ) for the same age group (figure 1D).
(A) 195.1 Orthostatic Hypotension

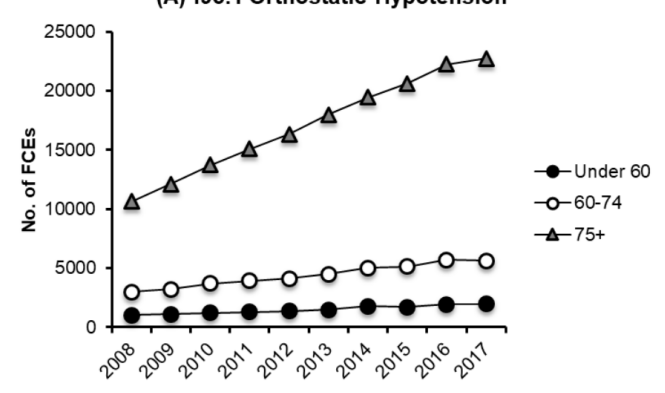

(B) R29.6 Tendency to fall, not elsewhere classified

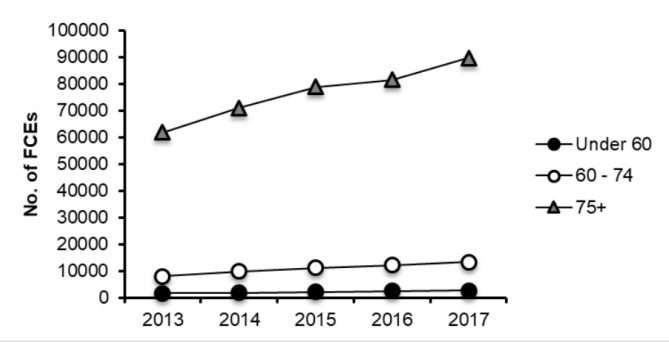

(C) G40 Epilepsy

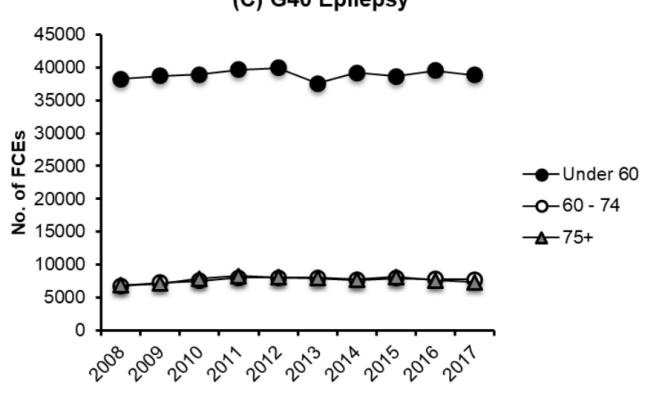

(D) J44 COPD

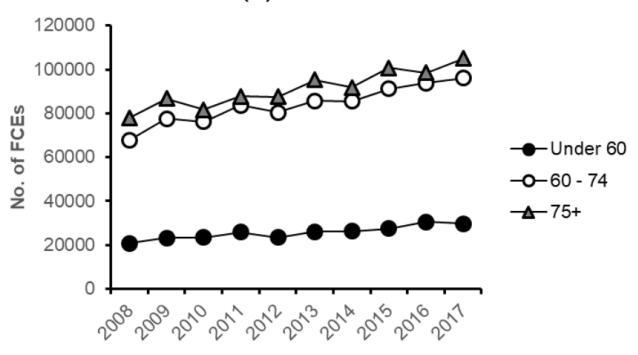

(E) Total FCEs

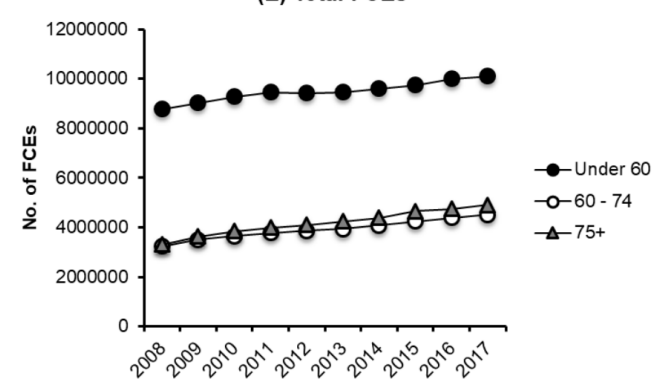

Figure 1 Number of finished consultant episodes (FCEs) per year by International Classification of Disease tenth revision code: (A) Orthostatic hypotension 195.1. (B) Tendency to fall R29.6, (C) Epilepsy G40. (D) Chronic obstructive pulmonary disease (COPD) J44. (E) Total FCEs per year, by age groups. 
During the same period overall admissions in NHS England rose by $28 \%$ from 15359062 to 19726907 . Admissions for over 75 years rose $48 \%$ from 3314849 to 4 912704 (figure 1E). FCEs for $\mathrm{OH}$ as a percentage of total FCEs for over 75 years increased from $0.32 \%$ to $0.46 \%$.

The admission rate for $\mathrm{OH}$ for the year 2017 was calculated as follows: (total admissions for $\mathrm{OH} 2017 \div$ population of England 2017) $\times 1000=0.55$ per 1000 person-years. This calculation however does not take into account the fact that a particular individual may have had more than one admission for $\mathrm{OH}$ in 2017.

\section{DISCUSSION}

In this analysis of discharge data from the HES database we have demonstrated that admissions for $\mathrm{OH}$ have risen significantly by $110 \%$ over a 10 -year period from 2008 to 2017 , with the greatest increase in the over 75 years age group. This increase is disproportionate to the rise in admissions overall, which rose $48 \%$ for those over 75 years in the same time period. This is also disproportionate to the increase in admissions for epilepsy and for COPD-7\% and 35\%, respectively. Admissions for falls have also increased in excess of expected rates-by $45 \%$.

Given that epilepsy and COPD are both widely prevalent in older persons, one would expect a proportionate increase as admissions for older people in general increase. The increase in admissions for $\mathrm{OH}$ however, far exceeds these.

The increase in admissions of persons aged 75 years and older is likely attributed to ageing demographics and multimorbidity in these age cohorts-over $80 \%$ of this cohort has multimorbidity. ${ }^{14}$ An English study in 2015 found that admissions in NHS England coded with frailty syndromes increased from 64559 to 150085 between 2005 and $2013 .^{15}$

Possible reasons for the disproportionate increase in $\mathrm{OH}$ are more aggressive treatment of hypertension and cardiovascular disorders. Increased awareness of the $\mathrm{OH}$ and more precise coding of the diagnosis could also contribute to the higher numbers of admissions for the diagnosis. It is not possible to differentiate these possibilities from the current data set, however in the National Audit of Inpatient Falls 2015 only $16 \%$ of the sample of 4846 patients had a lying and standing BP recorded by their third hospital day. ${ }^{16}$ This would suggest a low level of awareness of the issue and that the increase seen in admissions is unlikely to be due simply to changes in diagnosis and coding. In response to the National Audit of Inpatient Falls, the Royal College of Physicians published a lying and standing BP measurement guide in January 2017. ${ }^{17}$ However, the increase in admissions identified in our study precede these guidelines and thus cannot be attributed to the change.

Previous research on admissions for $\mathrm{OH}$ is limited, however, a population-based cohort study in Malmo of over 32000 people found a rate of hospital admission of $1.42 \%$ or 0.5 per 1000 person-years for $\mathrm{OH}$ and that rate increased with age and comorbidities. ${ }^{18}$ Admissions for $\mathrm{OH}$ were found to predict cardiovascular mortality. Given the differences in study population and methodology with this study it is difficult to compare rates of hospital admission for $\mathrm{OH}$. However we have calculated an admission rate for $\mathrm{OH}$ in NHS England of 0.55 per 1000 patient-years, similar to the rate in the Malmo study.

The strengths of our study include its robust, comprehensive source data and population coverage.

It is however observational data and as such we cannot infer causation. There is the possibility of misclassification bias given the reliance on hospital ICD-10 discharge coding. Furthermore, due to the limitations of the source data we were unable to control for confounding variables. Finally, as HES only includes patients admitted to hospital, those patients who present to the emergency department/ accident and emergency but are discharged directly from there will not have been included in our study.

In conclusion our results raise the question as to whether lower BP targets and more aggressive blood pressure control are to blame for the significant increase in admissions for $\mathrm{OH}$ in older people, however further research is needed to prove this hypothesis.

Contributors ED: obtained and analysed the data, drafted the manuscript. RR-0: assisted in drafting, editing and critically reviewing the manuscript. RAK: developed the concept, assisted in analysis of data, reviewing and editing of the manuscript.

Funding The authors have not declared a specific grant for this research from any funding agency in the public, commercial or not-for-profit sectors.

Competing interests None declared.

Patient consent for publication Not required.

Provenance and peer review Not commissioned; externally peer reviewed.

Data availability statement The data used in this study are freely available to all at: https://digital.nhs.uk/data-and-information/data-tools-and-services/dataservices/hospital-episode-statistics.

Open access This is an open access article distributed in accordance with the Creative Commons Attribution Non Commercial (CC BY-NC 4.0) license, which permits others to distribute, remix, adapt, build upon this work non-commercially, and license their derivative works on different terms, provided the original work is properly cited, appropriate credit is given, any changes made indicated, and the use is non-commercial. See: http://creativecommons.org/licenses/by-nc/4.0/.

ORCID iDs

Eoin Duggan http://orcid.org/0000-0001-8490-2076

Roman Romero-Ortuno http://orcid.org/0000-0002-3882-7447

\section{REFERENCES}

1 Office for National Statistics. National population projections for the UK, 2014-based, London 2015.

2 Freeman R, Wieling W, Axelrod FB, et al. Consensus statement on the definition of orthostatic hypotension, neurally mediated syncope and the postural tachycardia syndrome. Clin Auton Res 2011;21:69-72.

3 Fedorowski A, Melander O. Syndromes of orthostatic intolerance: a hidden danger. J Intern Med 2013;273:322-35.

4 Shaw BH, Borrel D, Sabbaghan K, et al. Relationships between orthostatic hypotension, frailty, falling and mortality in elderly care home residents. BMC Geriatr 2019;19:80.

5 Mol A, Bui Hoang PTS, Sharmin S, et al. Orthostatic hypotension and falls in older adults: a systematic review and meta-analysis. J Am Med Dir Assoc 2019;20:589-97.

6 Finucane $\mathrm{C}, \mathrm{O}^{\prime}$ Connell MDL, Donoghue O, et al. Impaired orthostatic blood pressure recovery is associated with unexplained and injurious falls. J Am Geriatr Soc 2017;65:474-82. 
7 Briggs R, Carey D, Kennelly SP, et al. Longitudinal association between orthostatic hypotension at 30 seconds Post-Standing and late-life depression. Hypertension 2018;71:946-54.

8 McNicholas T, Tobin K, Carey D, et al. Is baseline orthostatic hypotension associated with a decline in global cognitive performance at 4-Year Follow-Up? data from TILDA (the Irish longitudinal study on ageing). J Am Heart Assoc 2018;7:e008976.

9 Udow SJ, Robertson AD, Maclntosh BJ, et al. 'Under pressure': is there a link between orthostatic hypotension and cognitive impairment in $\alpha$-synucleinopathies? J Neurol Neurosurg Psychiatry 2016;87:1311-21.

10 Wright JT, Williamson JD, SPRINT Research Group,. Et al. A randomized trial of intensive versus standard blood-pressure control. N Engl J Med 2015;373:2103-16.

11 Garrison SR, Kolber MR, Korownyk CS, et al. Blood pressure targets for hypertension in older adults. Cochrane Database Syst Rev 2017;33.

12 Sexton DJ, Canney M, O'Connell MDL, et al. Injurious falls and syncope in older community-dwelling adults meeting inclusion criteria for sprint. JAMA Intern Med 2017;177:1385-7.
13 Kamaruzzaman S, Watt $\mathrm{H}$, Carson $\mathrm{C}$, et al. The association between orthostatic hypotension and medication use in the British women's heart and health study. Age Ageing 2010;39:51-6.

14 The Academy of medical sciences. multimorbidity: a priority for global health research. London 2018.

15 Soong J, Poots AJ, Scott S, et al. Quantifying the prevalence of frailty in English hospitals. BMJ Open 2015;5:e008456.

16 Royal College of Physicians. National audit of inpatient falls: audit report 2015. London: RCP, 2015.

17 Royal College of Physicians. . Measurement of lying and standing blood pressure: A brief guide for clinical staff. [Internet] London: RCP, 2017. Available: https://www.rcplondon.ac.uk/projects/outputs/ measurement-lying-and-standing-blood-pressure-brief-guideclinical-staff [Accessed cited 2019 Apr 25].

18 Ricci F, Manzoli L, Sutton R, et al. Hospital admissions for orthostatic hypotension and syncope in later life: insights from the Malmö preventive project. $J$ Hypertens 2017;35:776-83. 